\title{
Modern Analysis of Power Flow and Network Stability of Transmission Lines for Nuclear Power Dispatch
}

\author{
Swamynathan Kudiyarasan, Poundraj Sivakumar \\ Department of Atomic Energy, Fast Breeder Reactor, Bharatiya Nabhikiya Vidyut Nigam Limited, Kalpakkam, India
}

Email address:

kudiyarasan@rediffmail.com (S. Kudiyarasan)

To cite this article:

Swamynathan Kudiyarasan, Poundraj Sivakumar. Modern Analysis of Power Flow and Network Stability of Transmission Lines for Nuclear Power Dispatch. International Journal of Science, Technology and Society. Vol. 7, No. 1, 2019, pp. 21-32. doi: 10.11648/j.ijsts.20190701.14

Received: January 18, 2019; Accepted: March 2, 2019; Published: May 17, 2019

\begin{abstract}
This article presents an general approach to improve the power system planning, load flow pattern and stability of transmission lines using modern analysis concept. The objective is to categorize and characterize the existing system reliability concerns inherited from the adopted deterministic criteria, so that power utilities can accordingly adjust their reliability criteria to manage with real-life system uncertainties and hence to improve the overall system reliability. In the past many wide spread blackouts had occurred in interconnected power systems. Therefore it is necessary to ensure that grid should be operated economically and reliably. Contingency analysis is a well-known function in modern power system management. The aim of this analysis is to give the operator information about the static security, power flow pattern and stability. In general an outage largest capacity of one transmission line or transformer may lead to disturb the vital parameters in other lines. Modern analysis is used to calculate the violation on the network and improvement. Nuclear power plant is a base unit and best way to dispatch the power to the grid with minimum disturbance. This paper also shows the network stability, power flow management for 500MW Nuclear power plant transmission lines and connected to southern region network of India.
\end{abstract}

Keywords: Power Flow, Machine Angle, Stability Analysis, Transfer Function, Transmission Grid, Fault Analysis, Distribution Network

\section{Introduction}

BharatiyaNabhikiyaVidyut Nigam Limited (BHAVINI) is currently constructing a 500MWe Prototype Fast Breeder Reactor at Kalpakkam (KPFBR), $70 \mathrm{~km}$ away from Chennai. The KPFBR is the forerunner of the future Fast Breeder Reactors and is expected to provide energy security to the country. The KPFBR is being built with the design and technology developed at the Indira Gandhi Center for Atomic Research (IGCAR) located at Kalpakkam.

The plant is connected to the Tamil Nadu / Southern Regional Grid to transmit the power generated. A $230 \mathrm{kV}$ substation with six numbers of transmission lines namely One Double Circuit (D/C) to Sirucheri $(30 \mathrm{~km})$, One Double Circuit $(\mathrm{D} / \mathrm{C})$ to Kancheepuram $(70 \mathrm{~km})$ and One Double Circuit (D/C) to Arani $(85 \mathrm{~km})$. These substations are in turn connected to the $400 / 230 \mathrm{kV}$ substations at Melakottaiyur and Sriperumbudur which are connected to North Chennai Thermal Power Station and the $400 \mathrm{kV}$ grids. The interconnections planned provide reliable off-site power supply to the nuclear station.

The power system study to be carried out to ensure at least one of the off-site connections of switchyard is available even under various transients in the power system. The following prescribed transient one at a time shall be analyzed.

(a) Loss of the generating unit of KPFBR (500MWe Nuclear Power Plant)

(b) Loss of the largest generating unit of the concerned grid

(c) Loss of the largest transmission line or Inter - tie

(d) Loss of a double circuit from KPFBR Switchyard.

In addition to the above, maximum fault level at the generating plant of switchyard and fault levels at various grid nodes, and Dynamic over voltage are needs to be studied. In each of the above cases, it shall be checked that system should remain stable and at least one of the transmission lines remains connected to our $220 \mathrm{kV}$ KPFBR switchyard [1]. This study and analysis has been done based on the existing generation capacity and future generation envisaged in the 
area.

\section{Evolution of Transmission System Procedure}

The transmission system planning exercise is done based on power system studies on all the credible alternatives. These studies are performed utilizing power system analysis software in which entire All India electrical network up to $220 \mathrm{kV}$ level is simulated [3]. The transmission scheme for evacuation of power from KPFBR was planned in accordance with "Manual on Transmission Planning Criteria" of Central Electricity Authority (CEA) [17]. The salient criteria with regard to security and transient stability are:

\subsection{Criteria for Single Contingency ('N-1') - Steady State}

All the equipment in the transmission system shall remain within their normal thermal and voltage ratings after a disturbance involving loss of any one of the following elements (called single contingency or ' $\mathrm{N}-1$ ' condition), but without load shedding / rescheduling of generation:

(a) Outage of a $132 \mathrm{kV}$ or $110 \mathrm{kV}$ single circuit, or

(b) Outage of a $220 \mathrm{kV}$ or $230 \mathrm{kV}$ single circuit, or

(c) Outage of a $400 \mathrm{kV}$ single circuit, or

(d) Outage of a $400 \mathrm{kV}$ single circuit with fixed series capacitor(FSC), or

(e) Outage of an Inter-Connecting Transformer(ICT), or

(f) Outage of a $765 \mathrm{kV}$ single circuit

(g) Outage of one pole of HVDC bipole.

The angular separation between adjacent buses under (' $\mathrm{N}$ 1 ') conditions shall not exceed 30 degree.

\subsection{Criteria for Single Contingency ('N-1') - Transient Stability}

The transmission system shall be stable after it is subjected to one of the following disturbances:

1. The system shall be able to survive a permanent three phase to ground fault on a $765 \mathrm{kV}$ line close to the bus to be cleared in $100 \mathrm{~ms}$.

2. The system shall be able to survive a permanent single phase to ground fault on a $765 \mathrm{kV}$ line close to the bus. Accordingly, single pole opening $(100 \mathrm{~ms})$ of the faulted phase and unsuccessful re-closure (dead time 1 second) followed by 3-pole opening $(100 \mathrm{~ms})$ of the faulted line shall be considered.

3. The system shall be able to survive a permanent three phase to ground fault on a $400 \mathrm{kV}$ line close to the bus to be cleared in $100 \mathrm{~ms}$.

4. The system shall be able to survive a permanent single phase to ground fault on a $400 \mathrm{kV}$ line close to the bus. Accordingly, single pole opening $(100 \mathrm{~ms})$ of the faulted phase and unsuccessful re-closure (dead time 1 second) followed by 3 -pole opening $(100 \mathrm{~ms})$ of the faulted line shall be considered.

5. In case of $220 \mathrm{kV} / 132 \mathrm{kV}$ networks, the system shall be able to survive a permanent three phase fault on one circuit, close to a bus, with a fault clearing time of 160 $\mathrm{ms}$ ( 8 cycles) assuming 3-pole opening.

6. The system shall be able to survive a fault in HVDC convertor station, resulting in permanent outage of one of the poles of HVDC Bipole.

7. The system shall remain stable under the contingency of outage of single largest generating unit or a critical generating unit (choice of candidate critical generating unit is left to the transmission planner).

\subsection{Criteria for Second Contingency ('N-1-1')}

Under the scenario where a contingency as defined at above has already happened, the system may be subjected to one of the following subsequent contingencies (called ' $\mathrm{N}-1$ 1 ' condition [8]):

(a) The system shall be able to survive a temporary single phase to ground fault on a $765 \mathrm{kV}$ line close to the bus. Accordingly, single pole opening $(100 \mathrm{~ms})$ of the faulted phase and successful re-closure (dead time 1 second) shall be considered.

(b) The system shall be able to survive a permanent single phase to ground fault on a $400 \mathrm{kV}$ line close to the bus. Accordingly, single pole opening $(100 \mathrm{~ms})$ of the faulted phase and unsuccessful re-closure (dead time 1 second) followed by 3 -pole opening $(100 \mathrm{~ms})$ of the faulted line shall be considered.

(c) In case of $220 \mathrm{kV} / 132 \mathrm{kV}$ networks, the system shall be able to survive a permanent three phase fault on one circuit, close to a bus, with a fault clearing time of 160 $\mathrm{ms}$ ( 8 cycles) assuming 3-pole opening.

In the ' $\mathrm{N}-1-1$ ' contingency condition as stated above, if there is a temporary fault, the system shall not lose the second element after clearing of fault but shall successfully survive the disturbance.

In case of permanent fault, the system shall loose the second element as a result of fault clearing and thereafter, shall asymptotically reach to a new steady state without losing synchronism. In this new state the system parameters (i.e. voltages and line loadings) shall not exceed emergency limits, however, there may be requirement of load shedding /rescheduling of generation so as to bring system parameters within the normal limits.

\subsection{Additional Criteria for Nuclear Power Stations}

(a) In case of transmission system associated with a nuclear power station there shall be two independent sources of power supply for the purpose of providing start-up power. Further, the angle between start-up power source and the generation switchyard should be, as far as possible, maintained within 10 degrees.

(b) The evacuation system for sensitive power stations viz., nuclear power stations, shall generally be planned so as to terminate it at large load centers to facilitate islanding of the power station in case of contingency.

(c) Permissible normal and emergency limits.

(d) As per planning criteria of CEA [17], India, the 
permissible normal and emergency voltage limits are mentioned in table 1 below:

Table 1. Permissible normal and emergency voltage limits.

\begin{tabular}{|c|c|c|c|c|}
\hline \multicolumn{5}{|c|}{ Voltages $\left(k V_{\text {rms }}\right)$} \\
\hline \multirow{2}{*}{ Nominal } & \multicolumn{2}{|c|}{ Normal Rating } & \multicolumn{2}{|c|}{ Emergency Rating } \\
\hline & Max. & Min. & Max. & Min. \\
\hline 765 & 800 & 728 & 800 & 713 \\
\hline 400 & 420 & 380 & 420 & 372 \\
\hline 230 & 245 & 207 & 245 & 202 \\
\hline 220 & 245 & 198 & 245 & 194 \\
\hline 132 & 145 & 122 & 145 & 119 \\
\hline 110 & 123 & 99 & 123 & 97 \\
\hline 66 & 72.5 & 60 & 72.5 & 59 \\
\hline
\end{tabular}

As per sub-regulation $(\mathrm{m})$ of regulation 5.2 of Indian Electricity Grid Code (Second Amendment Regulations, 2014), "All Users, Southern Electricity Board (SEB), Southern Load Dispatch Center (SLDC), Regional Load Dispatch Center (RLDC), and Northern Load Dispatch Center (NLDC) shall take all possible measures to ensure that the grid frequency always remains within the [49.90 $50.05 \mathrm{~Hz}$ ] band".

The studies are done by carrying out load flow studies for normal as well as contingent operating conditions on all the identified alternatives. Results of these studies are compared based on power flow, estimated cost and overall system losses to arrive at the most techno-economic option [16]. The chosen alternative is then studied for transient disturbances through stability studies to determine the system behavior under transient faults and to ensure that the system is stable under all the contingencies prescribed in the Transmission Planning Criteria [17]. The results for the dynamic studies are presented in the form of machine angle variations following the disturbance to ascertain that the system remains stable. Further, the short circuit analysis is performed for subtransient $(\mathrm{t}=0)$ and transient $(\mathrm{t}=0.2$ Secs) time frames on the chosen alternative to determine the short circuit currents under single and/or three phase short circuit conditions.

\section{Major Considerations}

(a) The KPFBR has been envisaged with capacity of 500 MW. Considering the large unit capacity of $500 \mathrm{MW}$, alternative for $400 \mathrm{kV}$ transmission system has also been considered.

(b) The transmission system for evacuation of power from nuclear project should be constructed on separate corridors so that the power could be evacuated even under extreme contingency of tower outage.

\section{Data Considered for the Studies}

As mentioned above, for evolution of transmission system for evacuation of power from KPFBR, the entire all India system has been simulated for peak demand scenario. Southern region power system has been simulated in detail up to $220 \mathrm{kV}$ level. The load flow studies has been performed on the above-simulated data and checked for violations with respect to the bus voltages and transmission line loadings. The voltage limits considered for the bus voltages and thermal limits for the transmission lines are given at Table 2 andTable 3 [2]. Generation units in Southern Region are also considered. Load Generation Balance Report (LGBR) is also considered for the studies. Transfer Function Graph pertaining to Exciter, Stabilizer and Speed Governor is also considered along with plant (KPFBR) parameters.

Table 2. Voltage limits considered for studies.

\begin{tabular}{lll}
\hline Voltage $\left(\mathbf{k V}_{\mathbf{r m s}}\right)$ & & \\
\hline Normal & Maximum & Minimum \\
\hline 400 & 420 & 380 \\
230 & 245 & 207 \\
220 & 245 & 198 \\
\hline
\end{tabular}

Table 3. Thermal limits for the Transmission lines $\left(a t 85^{\circ} \mathrm{C}\right)$.

\begin{tabular}{llll}
\hline Line & Type of Conductor & Thermal limits for $\mathbf{4 5}^{\circ} \mathbf{C}$ ambient temp (in Amps) & Thermal limits for 50 ${ }^{\circ}$ ambient temp (in Amps) \\
\hline $400 \mathrm{kV}$ Twin & ACSR “MOOSE” & 1596 & 1428 \\
$230 \mathrm{kV} / 220 \mathrm{kV}$ & ACSR “ZEBRA” & 703 & 631 \\
$230 \mathrm{kV} / 220 \mathrm{kV}$ & AAAC “ZEBRA” & 700 & 627 \\
\hline
\end{tabular}

Total station loads considered at KPFBR is $50 \mathrm{MW}$ and generation voltage level is $21 \mathrm{kV}$. For load flow study, the maximum active power dispatch is considered at KPFBR i.e. $500 \mathrm{MW}$ while the reactive power limits are considered as 433 MVAR to +250 MVAR in line with the machine data of the manufacturer. Auto re-closer scheme for all the transmission lines at KPFBR end has dead time of $600 \mathrm{~ms}$.

\section{Transmission System Alternatives}

To evolve evacuation system of KPFBR, power system studies have been carried out for 2017-18 time frames where $500 \mathrm{MW}$ from KPFBR is available. While carrying out the studies, adequacy of the transmission system has been checked under normal and contingent conditions for different alternatives. These alternatives are compared on the basis of overall system losses and cost. For evacuation of power from KPFBR two alternatives have been considered.

\subsection{Alternative-I (400k V)}

(a) KPFBR - Malekottaiyur 400kV D/c line

(b) KPFBR - Arni $230 \mathrm{kV} \mathrm{D} / \mathrm{c}$ line

\subsection{Alternative-II (230kV)}

(a) KPFBR - Arni $230 \mathrm{kV} \mathrm{D} / \mathrm{c}$ line $(106.26 \mathrm{~km})$

(b) KPFBR - Sirucheri $230 \mathrm{kV} \mathrm{D} / \mathrm{c}$ line $(36.23 \mathrm{~km})$

(c) KPFBR - Kancheepuram $230 \mathrm{kV}$ D/c line $(80.34 \mathrm{~km})$ 


\subsection{Alternative-I $(400 \mathrm{kV})$}

To evacuate power from $500 \mathrm{MW}$ unit of Kalpakkam KPFBR, following $400 \mathrm{kV}$ and $230 \mathrm{kV}$ lines to nearby load centers have been considered:

(a) KPFBR - Malekottaiyur $400 \mathrm{kV}$ D/c line

(b) KPFBR - Arni $230 \mathrm{kV}$ D/c line

The simulation study has been carried out for base case and following contingency conditions:

(a) Base Case - Normal condition

(b) Outage of one ckt of KPFBR - Malekottaiyur 400kV $\mathrm{D} / \mathrm{c}$

(c) Outage of one ckt of KPFBR - Arni 230kV D/c

(d) Outage of 1ckt of KPFBR - Malekottaiyur $400 \mathrm{kV} \mathrm{D} / \mathrm{c}$ and 1 ckt of Bhavini - Arni $230 \mathrm{kV} \mathrm{D} / \mathrm{c}$

(e) Outage of both ckts of KPFBR - Arni 230kV D/c

(f) Outage of both ckts of KPFBR - Malekottaiyur 400kV $\mathrm{D} / \mathrm{c}$

From the studies it can be seen that as the generation is being stepped up at $230 \mathrm{kV}$, the major portion of power from the generation tends to flow through $230 \mathrm{kV}$ lines (about
$270 \mathrm{MW}$ ) while the flow on $400 \mathrm{kV}$ lines is only $170 \mathrm{MW}$. Under outage of both ckt of KPFBR - Malekottaiyur 400kV $\mathrm{D} / \mathrm{c}$ the entire power have to be evacuated by $230 \mathrm{kV}$ line [1]. The system is able to cater to normal condition but under $400 \mathrm{kV}$ line outage, $230 \mathrm{kV}$ line is being critically loaded.

\subsection{Alternative-II (230kV)}

In this alternative, $230 \mathrm{kV}$ lines to other load centers have been considered. Accordingly, following system has been considered under this alternative:

(a) KPFBR - Arni $230 \mathrm{kV}$ D/c line

(b) KPFBR - Sirucheri $230 \mathrm{kV}$ D/c line

(c) KPFBR - Kancheepuram $230 \mathrm{kV}$ D/c line

It may be noted that LILO of existing SP Koil Thiruvalam $230 \mathrm{kV}$ line at Kanchipuram S/s and LILO of Sunguvarchatram - Arni $230 \mathrm{kV}$ line at Kanchipuram S/s are ready for commissioning, hence same have been considered in the studies. The simulation study has been carried out for base case and following contingency conditions as show in table 4 .

Table 4. Normal Condition and Contingency Conditions.

\begin{tabular}{ll}
\hline Base Case-Normal Condition & Exhibit-Alt-II-Base \\
\hline Outage of one ckt of KPFBR - Arni 230kV D/c & Exhibit - Alt-II - 01 \\
Outage of one ckt of KPFBR - Sirucheri 230kV D/c & Exhibit - Alt-II - 02 \\
Outage of one ckt of KPFBR - Kancheepuram 230kV D/c & Exhibit - Alt-II - 03 \\
Outage of 1 ckt of KPFBR - Arni D/c and 1 ckt of KPFBR - Sirucheri D/c line & Exhibit - Alt-II - 04 \\
Outage of 1 ckt of KPFBR - Arni D/c and 1 ckt of KPFBR - Kancheepuram D/c line & Exhibit - Alt-II - 05 \\
Outage of 1 ckt of KPFBR - Kancheepuram D/c and 1 ckt of KPFBR - Sirucheri D/c & Exhibit - Alt-II - 06 \\
Outage of both ckts of KPFBR - Arni 230kV D/c & Exhibit - Alt-II - 07 \\
Outage of both ckts of KPFBR - Sirucheri 230kV D/c & Exhibit - Alt-II - 08 \\
Outage of both ckts of KPFBR - Kancheepuram 230kV D/c & Exhibit - Alt-II - 09 \\
\hline
\end{tabular}

From the studies, it can be seen that the system is able to cater to normal condition and contingency conditions and no constraints are envisaged in evacuation of power from KPFBR.

\section{Comparison of Alternatives}

It has been observed from the enclosed study that under alternative-II, power from KPFBR is being evacuated reliably under normal as well as contingency condition. In case of alternative-I only about $170 \mathrm{MW}$ power is dispatched through $400 \mathrm{kV}$ corridor while $270 \mathrm{MW}$ flows through $230 \mathrm{kV}$ line [1]. Further, under outage of one ckt of $230 \mathrm{kV} \mathrm{D} / \mathrm{c}$ line, other circuit get loaded to about $200 \mathrm{MW}$ and under outage of both ckt of KPFBR - Malekottaiyur $400 \mathrm{kV} \mathrm{D} / \mathrm{c}$ line, the entire power is being evacuated by $230 \mathrm{kV}$ line. Hence, in case of alternative-I, system is able to cater to normal condition, however under contingency condition, $230 \mathrm{kV}$ line is being critically loaded. While alternative-II connects KPFBR generation complex with Arni, Kanchipuram and Sirucheri which is connected further to Malekottaiyur and Thiruvalam. This system is more reliable, as under contingency, alternate paths are available for evacuation of power. This connectivity would help in evacuation of KPFBR power to load centers. In view of the above,
Alternative-II has been finalized for evacuation of KPFBR power.

\section{Load Flow Studies - Under Light Load Conditions}

The load flow studies have been conducted for light load conditions for the Alternative-II that has been chosen as the most techno-economic option. The case for light load condition has been simulated by considering regional load demand approximately $75 \%$ of the peak load demand. The reduction in load has been matched by equivalent reduction in generation, mostly hydro and Gas based. All the bus reactors andline reactors are in operation. The results of the load flow studies have been enclosed at Exhibit-ALT-II-LIGHT. From the studies, it has been observed that the voltages at different $\mathrm{kV}$ buses are well within their steady operating limits(1.05 p.u). The light load condition studies provide vital information about the reactive power absorption that the machine may be subjected under condition when the grid is expected to surplus in reactive power. The data at the generator terminals, for the KPFBR machines for light load conditions are as mentioned below in Table 5and Table 6 [11]. 
Table 5. Peak Load: MACHINE SUMMARY.

\begin{tabular}{llllllll}
\hline BUS\# & Name & BASKV & ID & MW & MVAR & QMAX & QMIN \\
\hline 541000 & KPFBR & 21.000 & 1 & 500 & 111.7 & 433.0 & -250.0 \\
ETERM & Current & PF & MVABASE & & & & \\
1.0000 & 512.3 & 0.9759 & 588.0 & & & & \\
\hline
\end{tabular}

Table 6. Light Load: MACHINE SUMMARY.

\begin{tabular}{llllllll}
\hline BUS\# & Name & BASKV & ID & MW & MVAR & QMAX & QMIN \\
\hline 541000 & KPFBR & 21.000 & 1 & 353.0 & 4.1 & 433.0 & -250.0 \\
ETERM & Current & PF & MVABASE & & & & \\
1.0000 & 353.1 & 0.9999 & 588.0 & & & & \\
\hline
\end{tabular}

\section{Stability Studies}

The stability studies were performed on the Alternative II that has been chosen as the most techno-economic option to study its behavior under transient/fault conditions [13]. As per the transmission planning criteria the system should be stable when subjected to following disturbances as prescribed in the Transmission Planning Criteria of CEA [17]:

(a) The system shall be able to survive a permanent three phase to ground fault on a $765 \mathrm{kV}$ line close to the bus to be cleared in $100 \mathrm{~ms}$.

(b) The system shall be able to survive a permanent single phase to ground fault on a $765 \mathrm{kV}$ line close to the bus. Accordingly, single pole opening $(100 \mathrm{~ms})$ of the faulted phase and unsuccessful re-closure (dead time 1 second) followed by 3 -pole opening $(100 \mathrm{~ms})$ of the faulted line shall be considered.

(c) The system shall be able to survive a permanent three phase to ground fault on a $400 \mathrm{kV}$ line close to the bus to be cleared in $100 \mathrm{~ms}$.

(d) The system shall be able to survive a permanent single phase to ground fault on a $400 \mathrm{kV}$ line close to the bus. Accordingly, single pole opening $(100 \mathrm{~ms})$ of the faulted phase and unsuccessful re-closure (dead time 1 second) followed by 3 -pole opening $(100 \mathrm{~ms})$ of the faulted line shall be considered.

(e) In case of $220 \mathrm{kV} / 132 \mathrm{kV}$ networks, the system shall be able to survive a permanent three phase fault on one circuit, close to a bus, with a fault clearing time of 160 $\mathrm{ms}$ (8 cycles) assuming 3-pole opening.

(f) The system shall be able to survive a fault in HVDC convertor station, resulting in permanent outage of one of the poles of HVDC Bipole.

(g) Contingency of loss of generation: The system shall remain stable under the contingency of outage of single largest generating unit or a critical generating unit.

Following studies has been conducted to ascertain the dynamic performance of the chosen alternatives. The result of the studies has been presented in the form of machine angle and power flows with respect to time as shown in Figure 4 to 12 and the Table 7 [9].

Table 7. The dynamic performance of the chosen alternatives.

\begin{tabular}{|c|c|c|c|c|}
\hline Sno & Case & Transient Fault considered & Exhibit No. & Type \\
\hline 1 & Case 1 & Dropping of one unit of 500MW at KPFBR after bus fault. & $\begin{array}{l}\mathrm{D}-1 \\
\mathrm{a} \text { and } b\end{array}$ & $\mathrm{~N}-1$ \\
\hline 2 & Case 2 & Dropping of one unit of $1000 \mathrm{MW}$ at KUNDANKULAM after bus fault. & $\begin{array}{l}\text { D-2 } \\
a \text { and } b\end{array}$ & $\mathrm{~N}-1$ \\
\hline 3 & Case 3 & 3-Ph fault on $1 \mathrm{ckt}$ of KPFBR - Arni $230 \mathrm{kV}$ D/c for $160 \mathrm{msec}$ followed by tripping of faulted line. & $\begin{array}{l}\text { D-3 } \\
a \text { and } b\end{array}$ & $\mathrm{~N}-1$ \\
\hline 4 & Case 4 & $\begin{array}{l}\text { Initially both circuits of KPFBR - Sirucheri } 230 \mathrm{kV} \text { D/c are online and outage of one circuit of } \\
\text { KPFBR - Sirucheri } 230 \mathrm{kV} \mathrm{D/c.}\end{array}$ & $\begin{array}{l}\text { D-4 } \\
\text { a and } b\end{array}$ & $\mathrm{~N}-1$ \\
\hline 5 & Case 5 & $\begin{array}{l}\text { Initially both circuits of KPFBR - Kancheepuram } 230 \mathrm{kV} \mathrm{D} / \mathrm{c} \text { are online and outage of one circuit of } \\
\text { KPFBR - Kancheepuram } 230 \mathrm{kV} \mathrm{D} / \mathrm{c} \text {. }\end{array}$ & $\begin{array}{l}D-5 \\
a \text { and } b\end{array}$ & $\mathrm{~N}-1$ \\
\hline 6 & Case 6 & Loss of largest transmission line or inter tie. & $\begin{array}{l}\text { D-6 } \\
\text { a andb }\end{array}$ & $\mathrm{N}-1$ \\
\hline 7 & Case 7 & Outage of both ckts of KPFBR - Arni $230 \mathrm{kV}$ D/c. & $\begin{array}{l}\text { D-7 } \\
\text { a andb }\end{array}$ & $\mathrm{N}-2$ \\
\hline 8 & Case 8 & Outage of both ckts of KPFBR - Sirucheri $230 \mathrm{kV}$ D/c. & $\begin{array}{l}\text { D-8 } \\
\text { a andb }\end{array}$ & $\mathrm{N}-2$ \\
\hline 9 & Case 9 & Outage of both ckts of KPFBR - Kancheepuram $230 \mathrm{kV}$ D/c. & $\begin{array}{l}\text { D-9 } \\
\text { a andb }\end{array}$ & $\mathrm{N}-2$ \\
\hline 10 & Case 10 & Tripping of largest transformer capacity supplying load at Malekottaiyur. & D-10 a andb & $\mathrm{N}-1$ \\
\hline 11 & Case 11 & $\begin{array}{l}\text { Initially both circuits of KPFBR - Arni } 230 \mathrm{kV} \text { D/c are online and outage of one circuit of KPFBR - } \\
\text { Arni } 230 \mathrm{kV} \mathrm{D/c} \text { after unsuccessful reclosure. }\end{array}$ & D-11 a andb & $\mathrm{N}-1$ \\
\hline 12 & Case 12 & $\begin{array}{l}\text { Initially both circuits of KPFBR - Kancheepuram } 230 \mathrm{kV} \text { D/c are online and outage of one circuit of } \\
\text { KPFBR - Kancheepuram } 230 \mathrm{kV} \text { D/c after unsuccessful reclosure. }\end{array}$ & D-12 a andb & $\mathrm{N}-1$ \\
\hline 13 & Case 13 & $\begin{array}{l}\text { Initially both circuits of KPFBR - Sirucheri } 230 \mathrm{kV} \mathrm{D} / \mathrm{c} \text { are online and outage of one circuit of } \\
\text { KPFBR - Sirucheri } 230 \mathrm{kV} \text { D/c after unsuccessful reclosure. }\end{array}$ & D-13 a andb & $\mathrm{N}-1$ \\
\hline
\end{tabular}


The mathematical model of speed governing system is shown in Figure 1. The corresponding parameter are tabulated as per the IEEE standard model in Table 8.

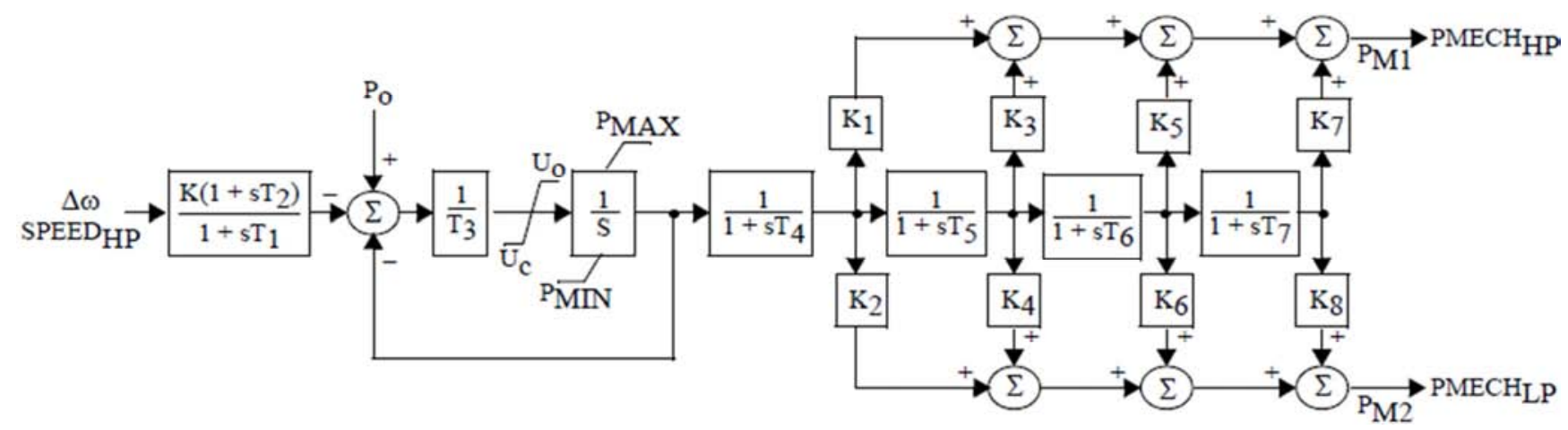

Figure 1. Transfer function Block Diagram of IEEEG1-1981 IEEE Type 1 Speed-Governing Model.

Table 8. Parameters of IEEE Type 1 Speed - Governing Model.

\begin{tabular}{llllll}
\hline Electrical & & Hyd & Constants & \\
\hline $\mathrm{T}_{1}$ & 0.10 & $\mathrm{~T}_{1}$ & 0.15 & $\mathrm{~K}_{1}$ & 20 \\
$\mathrm{~T}_{2}$ & 0.03 & $\mathrm{~T}_{2}$ & 0.00 & $\mathrm{~K}_{2}$ & 0.275 \\
$\mathrm{~T}_{3}$ & & & $\mathrm{~K}_{3}$ & 0.339 \\
$\mathrm{~T}_{4}$ & 0.10 & & $\mathrm{~K}_{4}$ & 0.387 \\
$\mathrm{~T}_{5}$ & 0.31 & & $\mathrm{P}_{\text {Min }}$ & 0.32 \\
$\mathrm{~T}_{6}$ & $\mathrm{~T}$ reheater+0.39 & & $\mathrm{P}_{\text {Max }}$ & 1.0 \\
\hline
\end{tabular}

The mathematical model of stabilizing model is shown in Figure 2. The corresponding parameter are tabulated as per the IEEE standard model in Table 9.

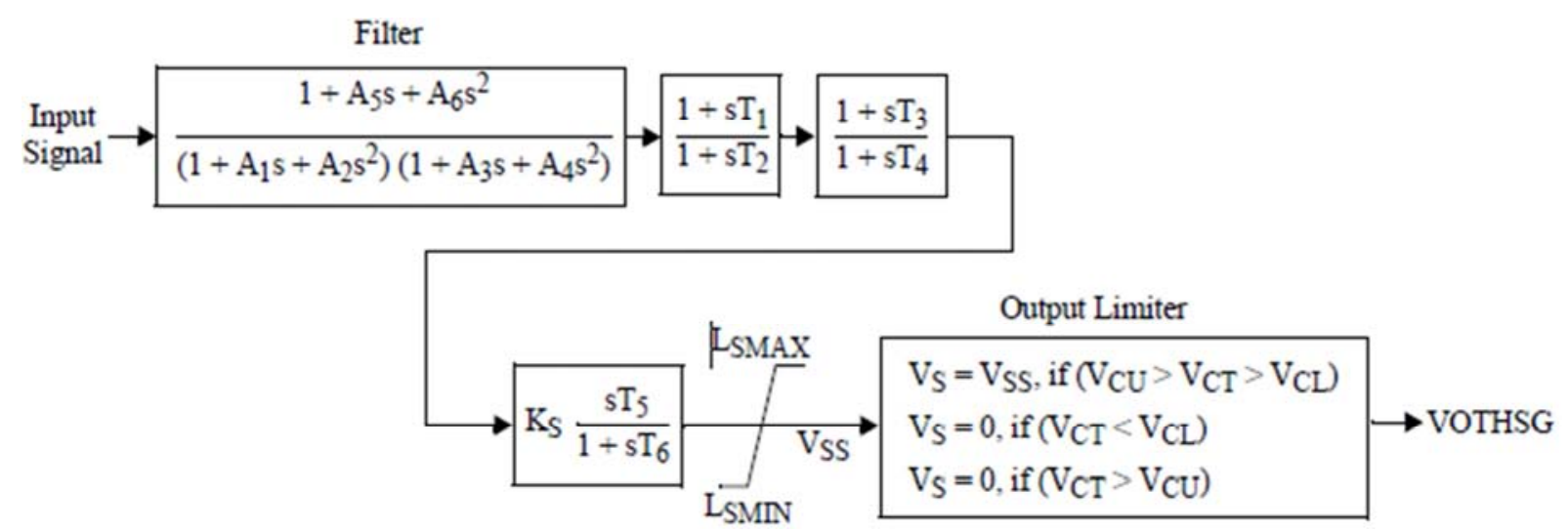

Figure 2. Transfer function Block Diagram of IEEEST-IEEE Stabilizing Model.

Table 9. Parameters of IEEEST-IEEE Stabilizing Model.

\begin{tabular}{llllll}
\hline Fun & Adj. Rang & FactSett & Fun & Adj. Rang & FactSett \\
\hline UGEX & $0-142 \%$ & $90 \%$ & TEX & $1-30 \mathrm{~s}$ & $5.0 \mathrm{~s}$ \\
IFEX & $0-300 \%$ & $30 \%$ & DEX & $33-900 \%$ & $100 \%$ s \\
Vo & $0-999$ & $70 \mathrm{pu}$ & K1 & - & $0.3 \mathrm{pu}$ \\
Vp1 & $10 \mathrm{pu}$ & K2 & - & $0.1 \mathrm{pu}$ \\
Vp2 & $15 \mathrm{pu}$ & POL & - & $0.2 \mathrm{pu}$ \\
Vi & Vp1 -Vo & $15 \mathrm{pu}$ & NOL & - & $-0.2 \mathrm{pu}$ \\
Ta & Vp1-5Vp1 & $1.0 \mathrm{~s}$ & Pmin & $0-100 \%$ & $10 \%$ \\
Tb & $0.1-30 \mathrm{~s}$ & $0.2 \mathrm{~s}$ & Umax & $0-142 \%$ & $125 \%$ \\
& $0.008-999 \mathrm{~s}$ & & Umin & $0-142 \%$ & $50 \%$ \\
\hline
\end{tabular}

The mathematical model of Excitation system model is shown in Figure 3. The corresponding parameter is tabulated as per the IEEE standard model in table 10. 


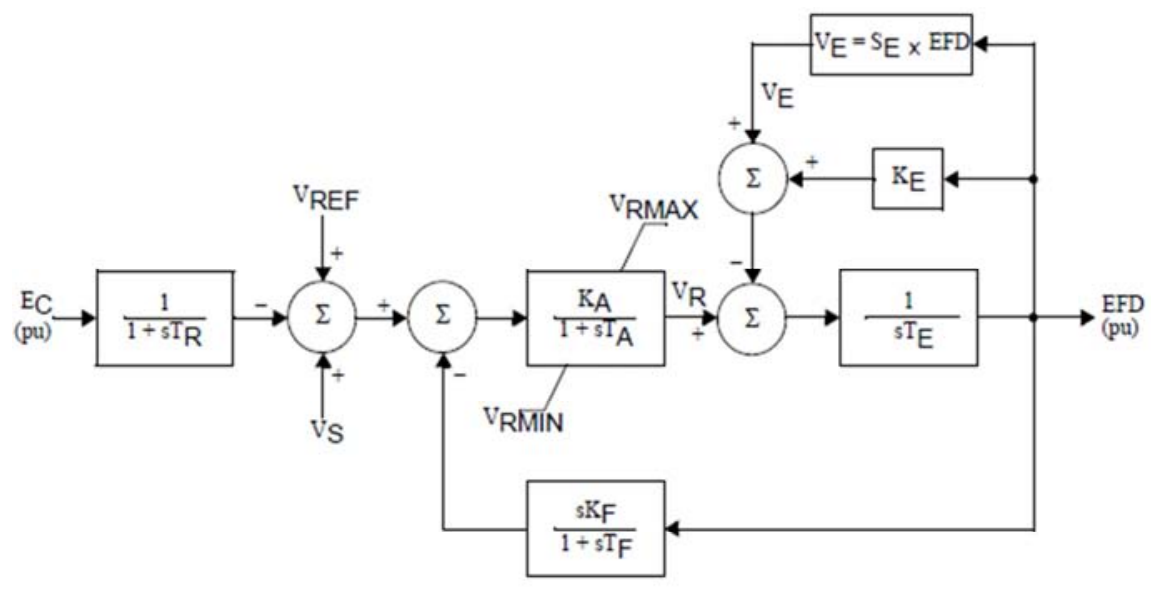

$\mathrm{V}_{\mathrm{S}}=\mathrm{VOTHSG}+\mathrm{VUEL}+\mathrm{VOEL}$

Note: $S_{E}$ is the saturation function.

Figure 3. Transfer function Block Diagram of IEEE- IEEE Type 1 Excitation System.

Table 10. Parameters of IEEE-IEEE Type 1 Excitation System.

\begin{tabular}{|c|c|c|c|c|c|}
\hline Tr Fn. para & Typical values & Unit & Tr Fn. para & Typical values & Unit \\
\hline $\mathrm{Tr}$ & 0.02 & $\mathrm{sec}$ & Kco & 0.16 & $\mathrm{pu}$ \\
\hline Tc2 & 0.2 (Note- 1 ) & $\sec$ & $\mathrm{Ke}$ & 1 & $\mathrm{pu}$ \\
\hline $\mathrm{Tb} 2$ & 0.13 (Note-1) & $\mathrm{sec}$ & $\mathrm{Te}$ & 1.706 & $\mathrm{sec}$ \\
\hline $\mathrm{KR}$ & 70 (Note-1) & $\mathrm{pu}$ & $\mathrm{T} 1$ & 0.02 & $\mathrm{sec}$ \\
\hline Tc1 & 1.0 (Note-1) & sec & $\mathrm{T} 2$ & 1.5 & $\mathrm{sec}$ \\
\hline Tb1 & 7 (Note-1) & $\mathrm{sec}$ & $\mathrm{T} 3$ & 0.02 & $\mathrm{sec}$ \\
\hline UP+ & +5.26 & $\mathrm{pu}$ & $\mathrm{T} 4$ & 1.5 & $\mathrm{sec}$ \\
\hline UP- & -5.26 & $\mathrm{pu}$ & Kss1 & -0.3 & $\mathrm{pu}$ \\
\hline $\mathrm{Up}+$ & +4.56 & $\mathrm{pu}$ & Kss2 & 0.1 & $\mathrm{pu}$ \\
\hline Up- & -4.56 & $\mathrm{pu}$ & Uss1Max & 0.2 & $\mathrm{pu}$ \\
\hline Ts & 0.003 & sec & Uss1Min & -0.2 & $\mathrm{pu}$ \\
\hline
\end{tabular}

These values are simulated in PSCAD. The responses of machine with various contingencies are shown in Figure 4 to 6.

Exhibit - D-2 a \& b Dropping of one unit of 1000MW at KUDANKULAM (largest generating unit)

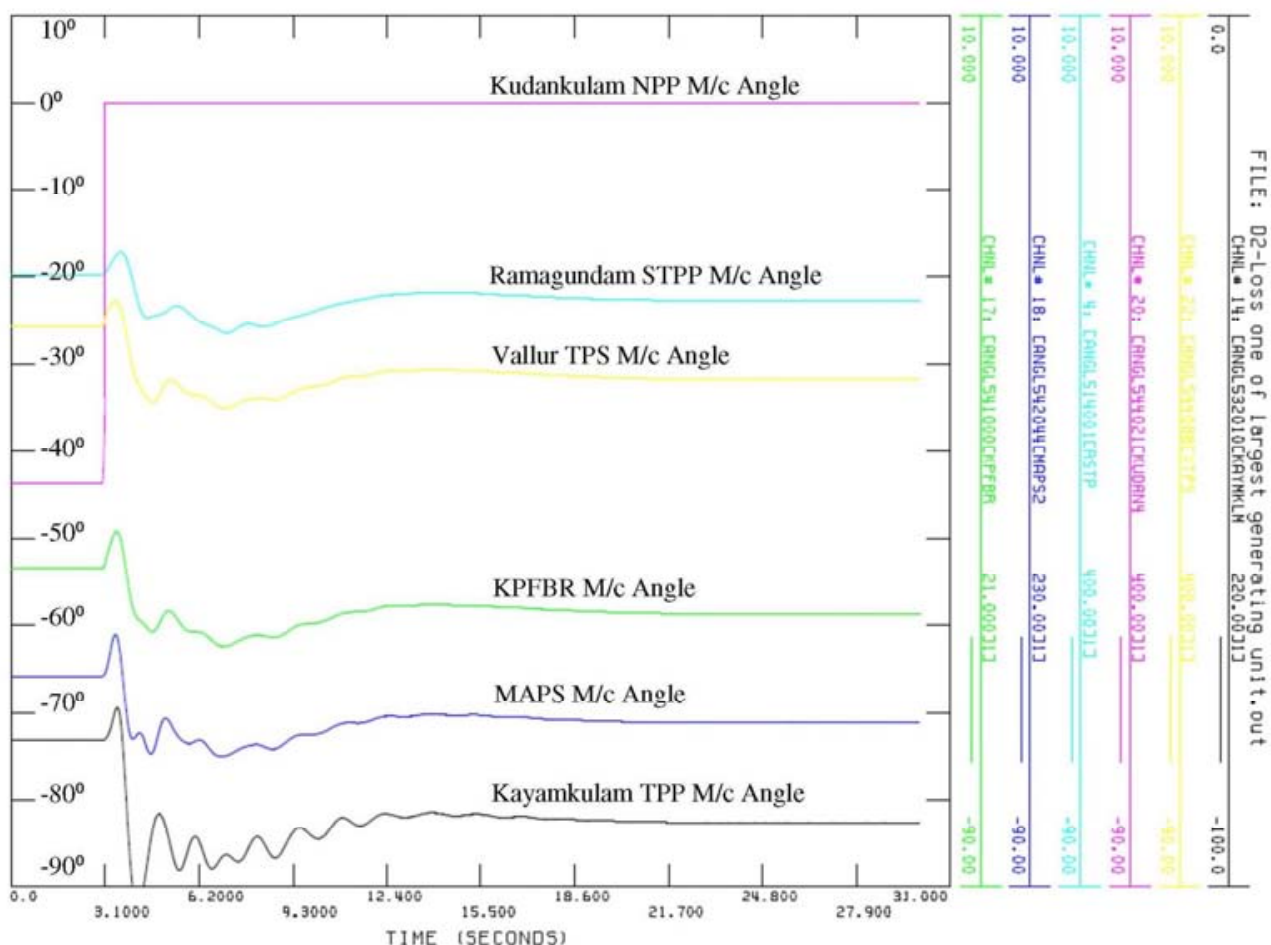



Stability of Transmission Lines for Nuclear Power Dispatch

FILE: D2-Loss one of largest generating unit.out

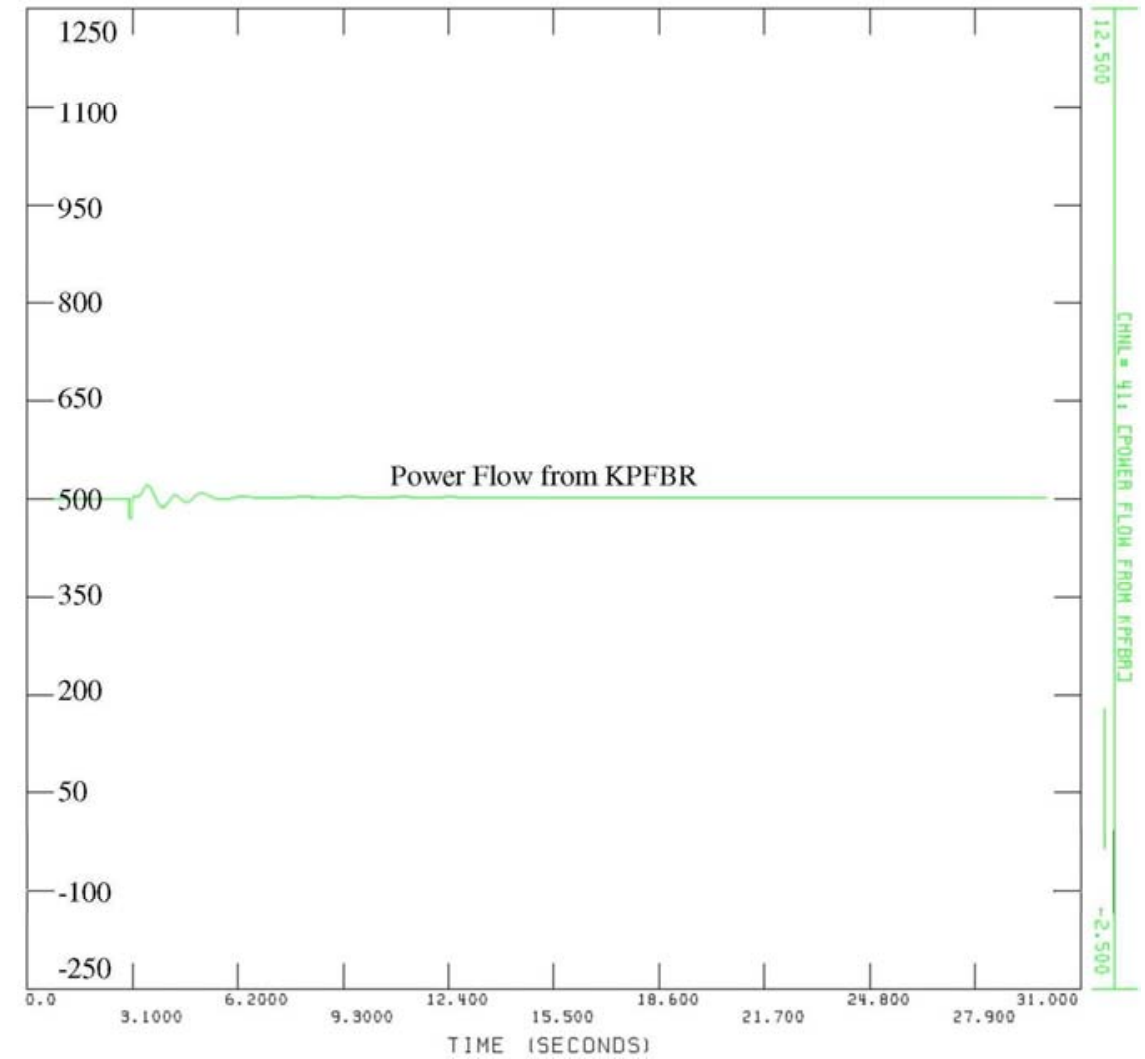

(b)

Figure 4. Machine Angle when dropping of one unit of 1000MW at Kudankulam Nuclear Plant (Largest Gen. Unit) (b). Power flow from KPFBR when dropping of one unit of $1000 \mathrm{MW}$ at KKNP (Largest Gen. Unit).

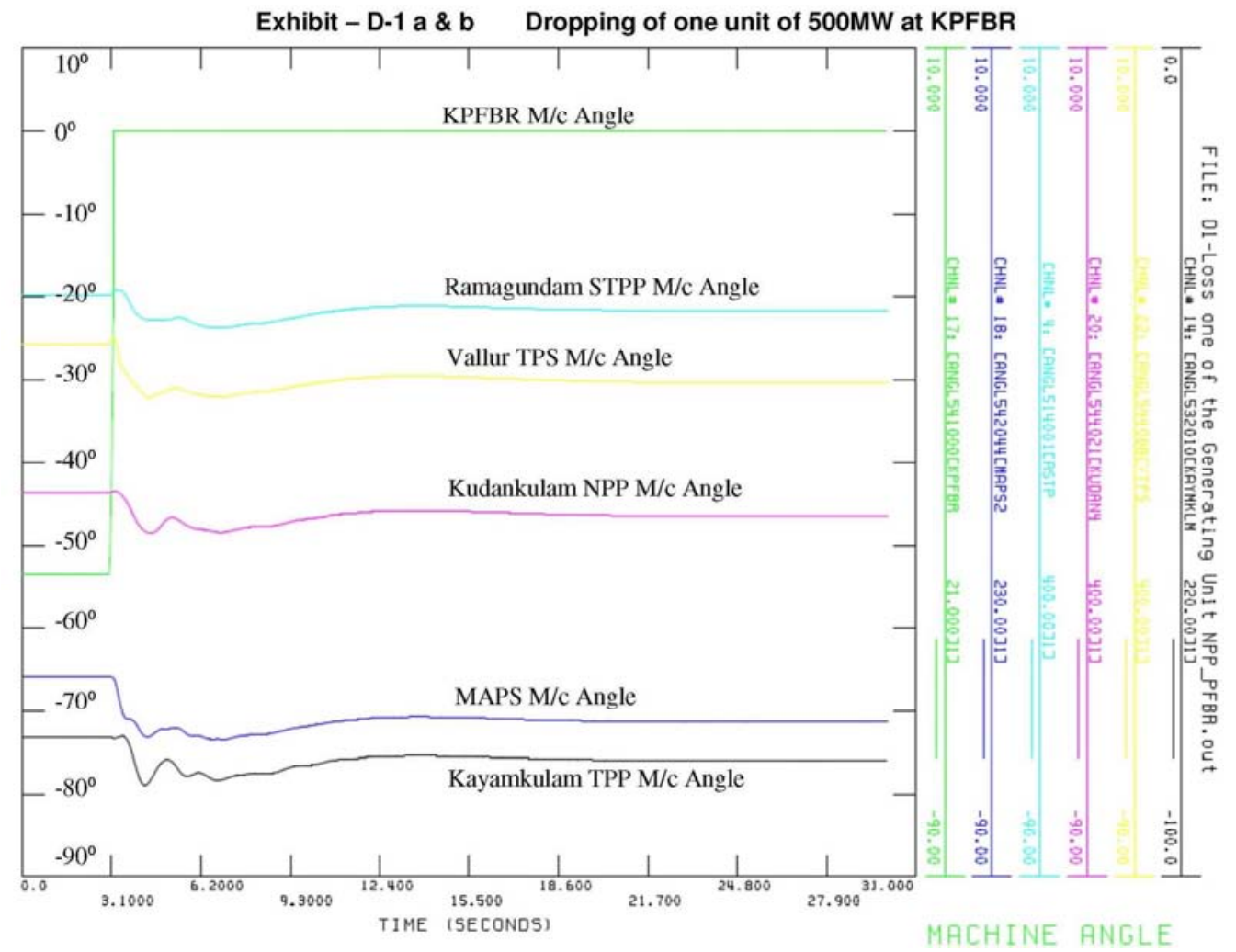


FILE: DI-Loss one of the Generating Unit NPP PFBR, out

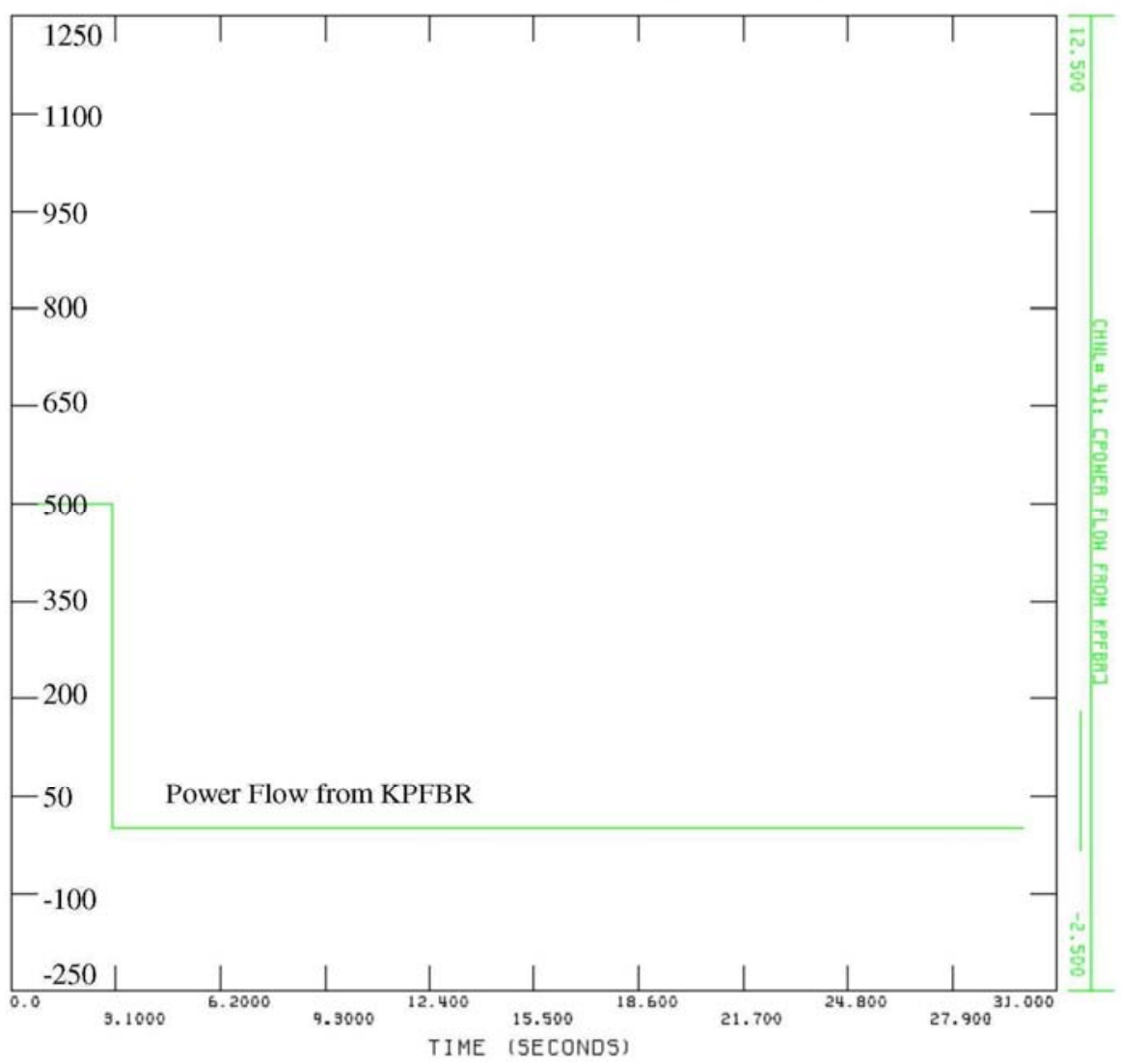

(b)

Figure 5. (a). Machine Angle when dropping of one unit of 500MW KPFBR, (b). Power flows from KPFBR when dropping of one unit of 500MW at KPFBR.

Exhibit - D-10 a \& b Tripping of largest transformer capacity supplying load at Malekottaiyur

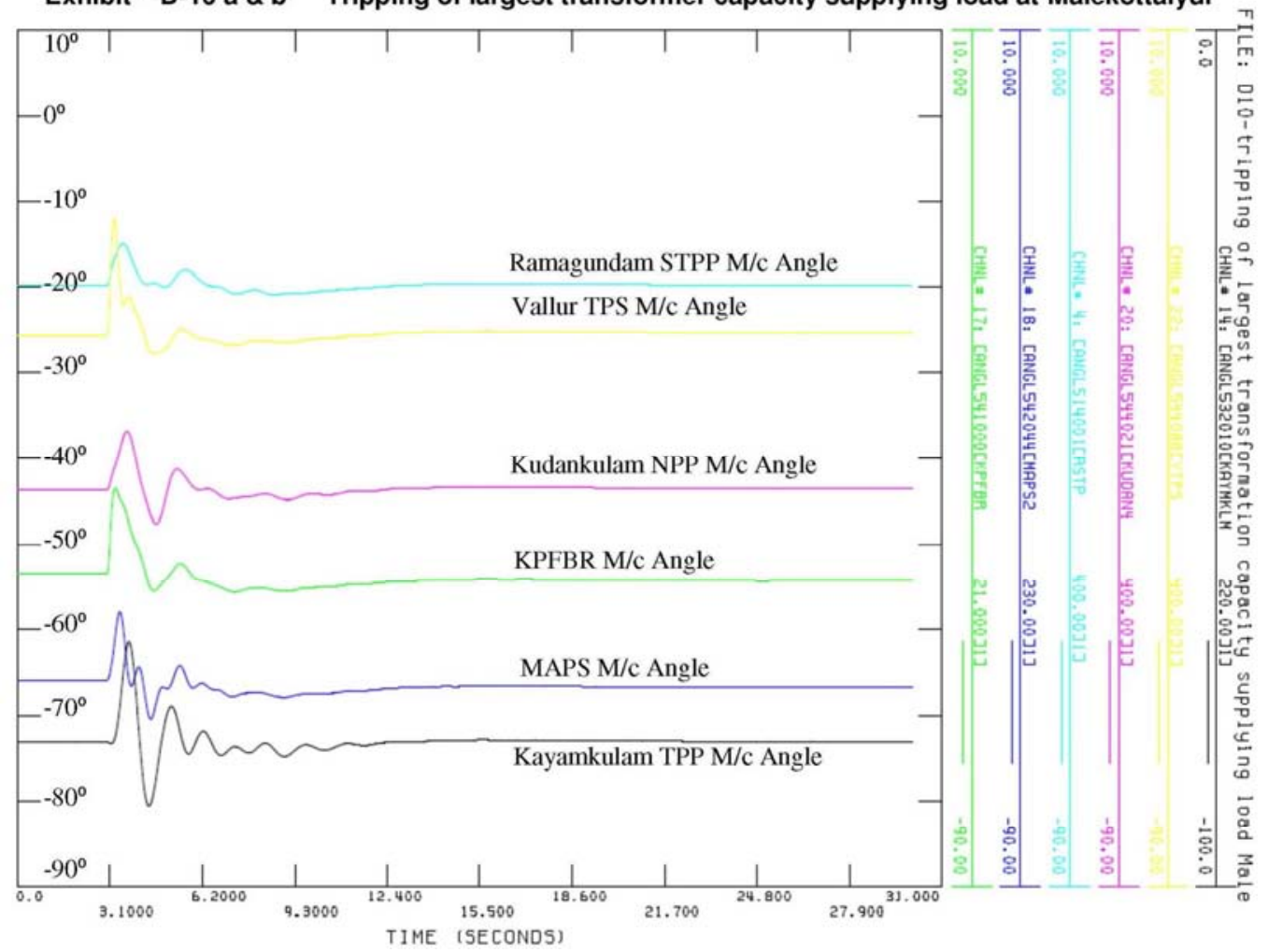

(a) 
FILE: D10-tripping of largest transformation capacity supplying load Male

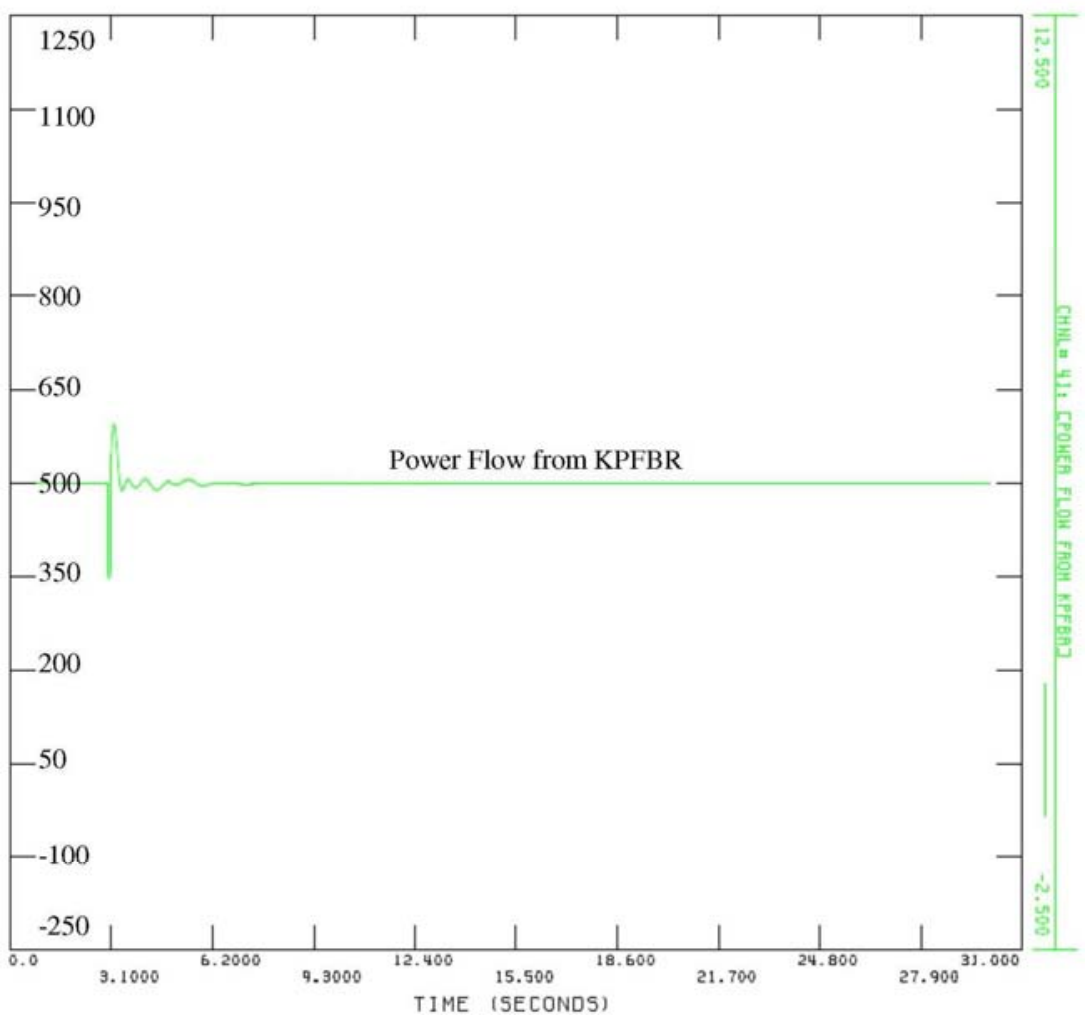

(b)

Figure 6.(a). Machine Angle when tripping of largest transformer capacity at Malekottaiyur. (b). Power flows from KPFBR when tripping of largest transformer capacity at Malekottaiyur.

Table 11. Final values of the transfer functions.

\begin{tabular}{lll}
\hline Test Report & Description & Gain Value \\
\hline $\mathrm{V} 0$ & Steady State Gain & 70 \\
$\mathrm{Vp} 1(\mathrm{Vp})$ & Proportional Gain & 10 \\
$\mathrm{~V} \infty$ & Gain at High frequencies & 15 \\
$\mathrm{Ta}$ & Integral Time Constant & 1.0 \\
$\mathrm{~Tb}$ & Differential Time const & 0.2 \\
\hline
\end{tabular}

The initial variation in machine angle depends on severity of fault [10]. However in general if the oscillations damp out to $10-15 \%$ after $20-30$ secs of fault, it is considered stable. From the above results Table 11, it has been observed that alternative- II is stable system under transient/ fault conditions for above faults [6].

\section{Short Circuit Studies}

Short circuit studies have been carried out foralternative-II. Short circuit currents for the single and three phase faults at major $230 \mathrm{kV}$ stations are calculated. Short circuit currents summary for the single and three phase faults at major stations close KPFBR are calculated $\mathrm{t}=0$ and $\mathrm{t}=0.2$ time frames and same have been enclosed at Exhibit - SC1 and SC2 respectively. From the studies, it is observed that short circuit levels at all the substations near KPFBR are well within the designed limits [5].

Further, the short circuit level along with their contributions has been determined for 220 and $400 \mathrm{kV}$ buses in the vicinity of KPFBR and Graphical plot for three phase and single phase fault for $\mathrm{t}=0$ and $\mathrm{t}=0.2$ is also arrived at Exhibit-SC1-3ph, Exhibit-SC1-1ph, Exhibit-SC2-3ph and Exhibit-SC2-1ph [12].

\section{Dynamic over Voltage Studies}

Dynamic over Voltages are the power frequency over voltages that are experienced at the receiving end of transmission lines following a sudden "load rejection". The magnitude of these voltages depends on the length of transmission line, strength of the system at the sending end and active and reactive power flow prior to the load rejection. These voltages are generally controlled through line reactors at the receiving end. As per the Manual on Transmission Planning Criteria [17], DOV for $230 \mathrm{kV}$ transmission lines should be limited to 1.8 p.u $(360 \mathrm{kV})$ (peak) phase to neutral $[4,7]$.

The DOV studies in the present studies have been performed using PSCAD software. The results of the DOV studies for the different transmission lines considered for the 
evacuation of KPFBR is as show in Figure 7(a), (b) and (c) and Table 12.

EXHIBIT - G1

Results of DOV study for KPFBR - Arni line

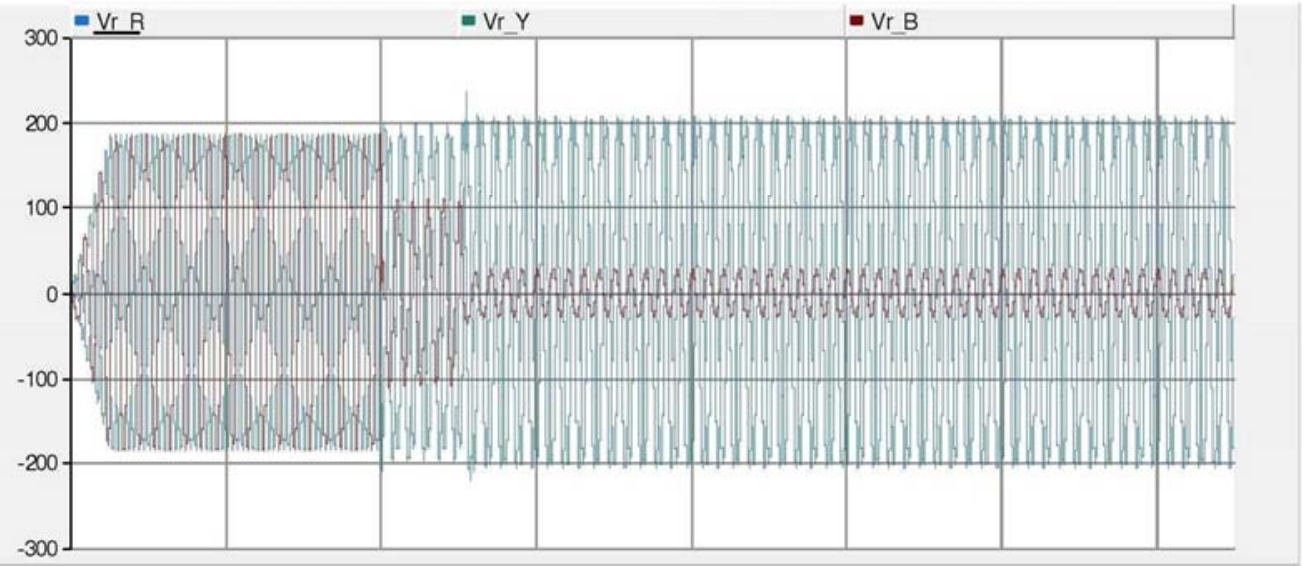

(a). $\mathrm{Y}$ axis - $\mathrm{kVp}, \mathrm{X}$ axis- time in $\mathrm{ms}$

EXHIBIT - G3 Results of DOV study for KPFBR - Kancheepuram line

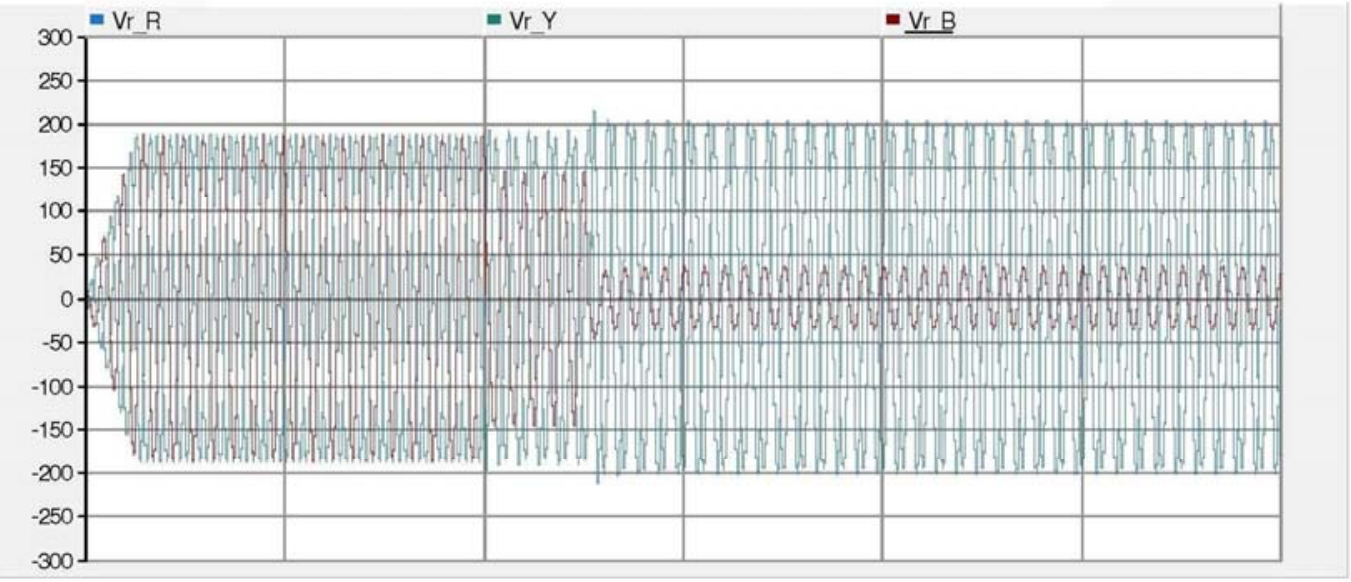

(b). $Y$ axis - $k V p, X$ axis- time in $\mathrm{ms}$

EXHIBIT - G2

Results of DOV study for KPFBR - Sirucheri line

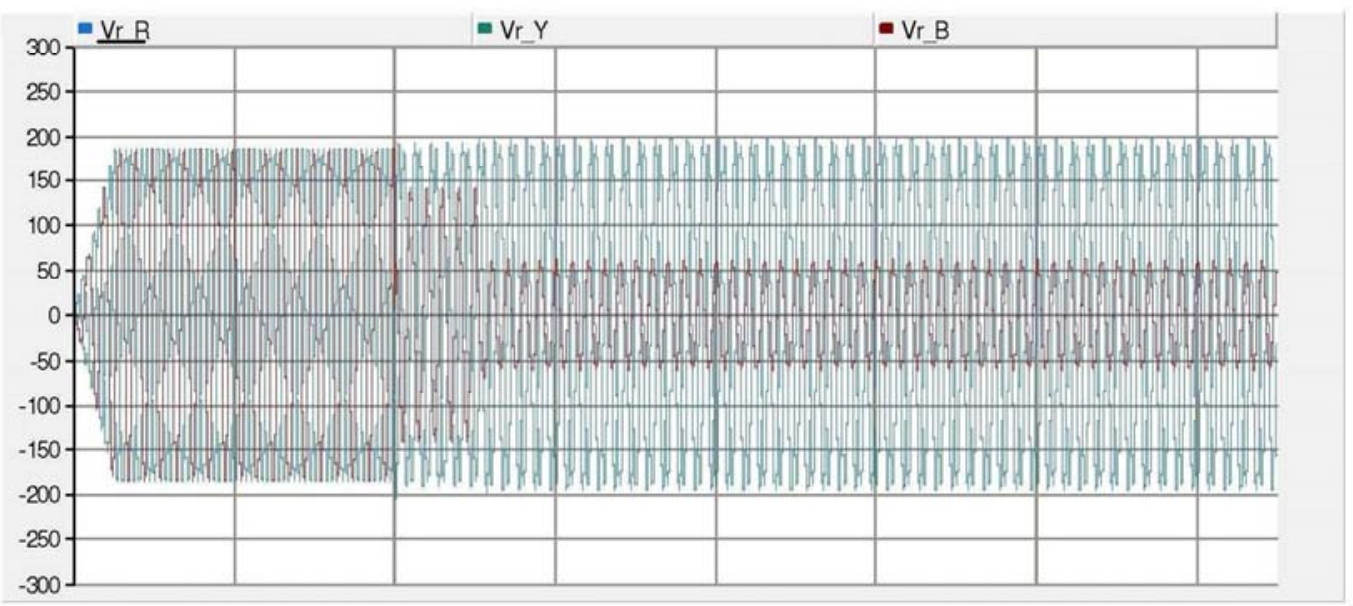

(c). $\mathrm{Y}$ axis - $\mathrm{kVp}, \mathrm{X}$ axis- time in $\mathrm{ms}$

Figure 7. (a). Results of DOV study for Arni $230 \mathrm{kV}$ line, (b). Results of DOV study for Kanchi $230 \mathrm{kV}$ line, (c). Results of Dynamic Over Voltage (DOV) study for Sirucheri $230 \mathrm{kV}$ line. 
Table 12. DOV results for different transmission lines.

\begin{tabular}{lll}
\hline Transmission Lines & DOVobserved & Exhibit No. \\
\hline KPFBR - Arni 230kV D/c Line & 1.097 p.u.(182 kVp) & G-1 \\
KPFBR - Sirucheri 230kV D/c Line & 1.038 p.u.((192 kVp) & G-2 \\
KPFBR - Kancheepuram 230kV D/c Line & 1.065 p.u.(187 kVp) & G-3 \\
\hline
\end{tabular}

It has been observed from the results that DOV on the transmission lines are well below the limit stipulated in the Transmission Planning Criteria [17].

\section{Conclusion}

The stability, power flow, short-circuitand DOV studies have been performed in line with the Transmission Planning criteriain the KPFBR transmission lines and the test results are well within the stipulated limits. The results of the load flow studies have been observed that the voltages at different buses (in $\mathrm{kV}$ ) are well within their steady operating limits (1.05 p.u) [14]. The initial variation in machine angle depends on severity of fault and in general if the oscillations damp out to $10-15 \%$ after $20-30$ secs of fault, it is considered stable.

From the short circuit studies, it is confirmed that short circuit levels at all the substations near KPFBR are well within the designed limits. The Dynamic Over voltage studies it is confirmed from the results are well below the limit stipulated in the Transmission Planning criteria. Finally it has been confirmed that the prosed system is a stable system under any transient or fault conditions [15] by using the modern analysis technics. The simulation result also showsthat the modeling has enough accuracy to meet the demand of power system calculation.

\section{Acknowledgements}

The authors would like to acknowledge the Technical support and sharing grid parameters from Power Grid Corporation of India Limited (PGCIL).

\section{References}

[1] Rafael Espejo, Sara Lumbreras, Andres Ramos," Analysis of transmission-power-grid topology and scalability the European case study", Journal of Physica A 509 (2018) 383395 ,

[2] J. C. Castro-Galeano, W. J. Cabra-Sarmiento, and J. F. OrtizPortilla, "Fault and load flows analysis of electricity transmission and distribution system in Casanare (Colombia)," Journal of Rev. Fac. Ing., vol. 26 (44), pp. 9-21, Ene. 2017.

[3] Tofael Ahmeda, S. Mekhilefa, Rakibuzzaman Shahb, N. Mithulananthanc," Investigation into transmission options for cross-border power trading in ASEAN power grid “, Journal of Energy Policy 108 (2017) 91-101 .

[4] N Christl, R Hedig R Johnson, P Krause, A Montoya,"Power System Studies And Modelling For The Kayenta $230 \mathrm{kV}$ Substation Advanced Series Compensation", Journal of Siemen Land Western Area Power Administration USA pp. 33-37.
[5] Y. Shi, H. D. Tuan, P. Apkarian, A. V. Savkin, “Global optimal power flow over large-scale power transmission Networks", Journal of Systems and Control Letters 118 (2018) 16-21.

[6] E. Cinieri, Senior Member, IEEE and A. Carrus, F. M. Gatta,"Avoiding System Collapses By Centralized Control of Power Flows Through The Interconnections Between Two Transmission Systems".

[7] B. Kawkabani, Member, IEEE, Y. Pannatier, J.-J. Simond, Member, IEEE,"Modeling and Transient Simulation of Unified Power Flow Controllers (UPFC) in Power System Studies", Journal of IEEE PowerTech 2007, pp. 333-338.

[8] Yang Feng, Daniel Tylavsky,“A Holomorphic embedding approach for finding the Type-1 power-flowSolutions", Journal of IEEEElectrical Power and Energy Systems 102 (2018) 179-188.

[9] Amadou Oury Ba, Tao Peng, and Serge Lefebvre,"Rotary Power-Flow Controller for Dynamic Performance Evaluation-Part II: RPFC Application in a Transmission Corridor", Journal of IEEE TRANSACTIONS ON POWER DELIVERY, VOL. 24, NO. 3, JULY 2009.

[10] M. Li, X. S. Han and M. Yang,"Study on the Transmission PerformanceIndex of the Complex Power Grid".

[11] A. V. Naresh Babu and S. Sivanagaraju,"Mathematical Modelling, Analysis and Effects of Interline Power Flow Controller (IPFC) Parameters in Power Flow Studies".

[12] Masoud GhiafehDavoudi, Amir Bashian, JafarEbadi,"Effects of Unsymmetrical Power Transmission System on the Voltage Balance and Power Flow Capacity of the Lines", Journal of International Electro Technical Commission, 978-1-4577$1829-8 / 12 / \$ 26.00$ C2012 IEEE.

[13] O. H. Abdalla, A. Al-Busaidi, H. Al-Hadi, H. Al-Riyami, A. Al-Nadabi, K. Karoui and A. Szekut,"Dynamic Assessment of Voltage and Reactive PowerControl in Oman Transmission System", IEEE 8th International Power Engineering and Optimization Conference (PEOCO2014), Langkawi, The Jewel of Kedah, Malaysia. 24-25 March 2014.

[14] Antriksh Songh, Thomos Frei, Ndaona Chokani, Reza S. Abhari, "Impact of unplanned power flows in interconnected transmission systems-Cse study of Central Eastern European region", Energy Policy 91 (2016) pp. 287-303.

[15] Wijarn WANGDEE,"Deterministic-based power grid planning enhancement using system well-being analysis", J. Mod. Power Syst. Clean Energy (2018) 6(3):438-448.

[16] Veenavati Jagadishprasad mishra, Manisha D. Khardenvis, "Contigency Analysis of Power System", International Confrence on Emerging Frontiers in Technology for Rural Area (EFITRA) 2012.

[17] "Manaual on Transmission Planning Criteria", Central Electricity Authority, NewdelhiIndia, 2013. 